\section{An Aqueous Extract of the Leaves of Ficus religiosa In- hibits the Growth of Urinary Calcium Hydrogen Phosphate Dihydrate Crystals-An In-Vitro Study}

Baskaraboopathy $A^{1}$, Rajaram MG $^{1}$, Elizabeth $A R^{1}$, Eevera $T^{1}$ and Jayakumar $\mathrm{T}^{2^{*}}$

${ }^{1}$ Department of Biotechnology, Periyar Maniammai University, Tamil Nadu, India

${ }^{2}$ Department of Pharmacology, Graduate Institute of Medical Sciences, Taipei Medical University, Taipei, Taiwan

\begin{abstract}
Background: Ficus religiosa $L$ (Lauraceae) has been shown to have numerous biological activities such as wound healing, antibacterial, anticonvulsant, antidiabetic and antiinflammatory. However, the effects of this plant on Calcium Hydrogen Phosphate Dihydrate (CHPD) urinary crystals remain obscured. The present study investigated the inhibitory action of an aqueous extract of the Ficus religiosa ( $F$. religiosa) leaves on the growth of CHPD crystals.

Methods: CHPD crystals were grown as a urinary type using single diffusion gel technique in silica hydro-gels. An extract $(50,75$ and $100 \%$ ) of the leaves of $F$. religiosa was added over to CHPD crystals growth for 12 days to evaluate its inhibitory effect. Thermogravimetric (TGA) and powder X-ray diffraction analyses were performed to characterize the cultured CHPD crystals.

Results: A 75 and $100 \%$ aqueous extracts of the leaves of $F$. religiosa was significantly $(P<0.05$ and 0.01 , respectively) reduced CHPD crystals growth and the inhibition rate was almost $>50 \%$. Whereas, a moderate inhibition $(P<0.05)$ of $C H P D$ crystal growth was found in $75 \%$ of aqueous leaf extracts of $F$. religiosa. However, $50 \%$ of aqueous leaf extracts of $F$. religiosa exhibit no inhibition on the CHPD crystal growth.
\end{abstract}

*Corresponding author: Jayakumar T, Department of Pharmacology, Graduate Institute of Medical Sciences, Taipei Medical University, 250 Wu-Hsing Street, Taipei 110, Taipei, Taiwan, Tel: +886 227361661; Extn: 3205; Fax: +886 227390450; E-mail: tjaya_2002@yahoo.co.in

Citation: Baskaraboopathy A, Rajaram MG, Elizabeth AR, Eevera T, Jayakumar T (2017) An Aqueous Extract of the Leaves of Ficus religiosa Inhibits the Growth of Urinary Calcium Hydrogen Phosphate Dihydrate Crystals-An In-Vitro Study. J Altern Complement Integr Med 3: 041.

Received: July 18, 2017; Accepted: October 25, 2017; Published: November 09,2017
Conclusion: These results indicate that the higher concentration of the leaf extracts of $F$. religiosa is highly responsible for the inhibition of CHPD crystal growth. This study may suggest that $F$. religiosa can be used as therapeutic agent for the treatment of urinary calculi or their prevention.

Keywords: CHPD crystals; Ficus religiosa L; Liesegang ring; Powder X-ray diffraction; Thermogravimetry

\section{Introduction}

Urolithiasis, also called calculi or uroliths, is a condition which involves the process of stone formation in the kidney, bladder and/ or urethra. Kidney stones are a general cause of blood in the urine and pain in the abdomen and flank, with a reported incidence about $12 \%$ in the general population [1]. There are numerous theories for the development of the urinary calculi $[2,3]$. The nucleation theory proposes that urinary stones originate from the crystals present in supersaturated urine. The crystal-inhibitor theory, furthermore, suggests that calculi form due to the absence or low concentrations of the host's natural stone inhibitors. The development of urinary calculi can be simulated in the laboratory by growing crystals in a silica hydro gel medium. This growth of urinary crystals in silica hydro gel can be considered as a simplified in vitro model for the highly complex growth of urinary calculi in vivo.

The development of crystals in the gel is the simplest techniques under ambient environments which is appropriate for the crystal growth of compounds sparingly soluble and which decompose at low temperatures. India is expected to have urinary stones at about $12 \%$ of the population and out of that about $50 \%$ of cases encounter loss of one or both kidneys. It has been shown that upper as well as lower urinary tract stones arise habitually, but in India the incidence shows wide variation on the regional basis [4]. Therefore, it is essential to find for an alternative means such as medicinal plants or phytotherapy [5]. Data from in vitro, in vivo studies and clinical trials reveal that phytotherapeutic agents could be useful as either an alternative or an adjunctive therapy in the management of urolithiasis [6].

Ficus religiosa L. (Lauraceae), is widely branched with longtipped, leathery heart shaped leaves and purple fruits growing in pairs. It has mythological, religious and medicinal importance in Indian culture since ancient times $[7,8]$. This plant has long been used in traditional medicine for various disorders and its different parts have been used medicinally in various forms as well as in combination with other herbs. This plant has been shown to have numerous biological activities such as wound healing, antibacterial, anticonvulsant, antidiabetic, antiinflammatory and acetyl cholinesterase inhibitory activity [8-13]. The acetone extract of $F$. religiosa leaves has been shown to induce apoptosis in breast cancer cell lines [14]. Choudhari et al., have reported the antioxidant and cytotoxic activity of $F$. religiosa bark against cervical cancer cells [15]. A recent study has reported the anti-ulcer activity of the ethanolic extract of $F$. religiosa leaf [16]. Antitumor activity of biosynthesized silver nanoparticles using $F$. religiosa as a nanofactory in Dalton's Ascites Lymphoma (DAL) induced mice has recently been reported by [17]. In the present study, 
for the first time we aimed at investigating the efficacy of $F$. religiosa on CHPD crystals growth in vitro.

\section{Materials and Methods}

\section{Growth of CHPD crystals}

The gel technique is found to be promising method to grow CHPD crystals as described by Joshi and Joshi, 2003 [18]. This technique provides much simplified method to understand the growth of urinary crystal in vitro. The formation of Liesegang rings was observed in the presents study. Glass test tubes were used as a crystallization apparatus and the single diffusion reaction technique was employed. One of the reactants, $1 \mathrm{M}$ orthophosphoric acid, was mixed with sodium metasilicate solution having a specific gravity of $1.04 \mathrm{~g} / \mathrm{cm}^{3}$. After obtained a clear transparent gel of optimum porosity, the supernatant solution of $1 \mathrm{M}$ calcium chloride was gently poured onto the set gel in various test tubes. The experiments were repeated three times and each time three test tubes were used for the same supernatant solution. After pouring on each supernatant solution, the test tubes were capped with airtight stopples. The experiments were conducted at room temperature $\left(\sim 37^{\circ} \mathrm{C}\right)$. The growth parameters of CHPD crystals are given in table 1.

\section{Collection Ficus religiosa L. (Lauraceae) and its extract preparation}

Fresh leaves of F. religiosa (Figure 1A) were collected (2007 November) from the Botanical garden of Periyar Maniammai University, Vallam, Tamil Nadu, India. The plant material was verified by Dr. T Eevera, Professor Department of Biotechnology, Periyar Maniammai University. Collected plant specimen was systematically tagged, pressed, dried and mounted on herbarium sheets. Voucher specimens were deposited in the Department of Biotechnology, Periyar Maniammai University for future reference.

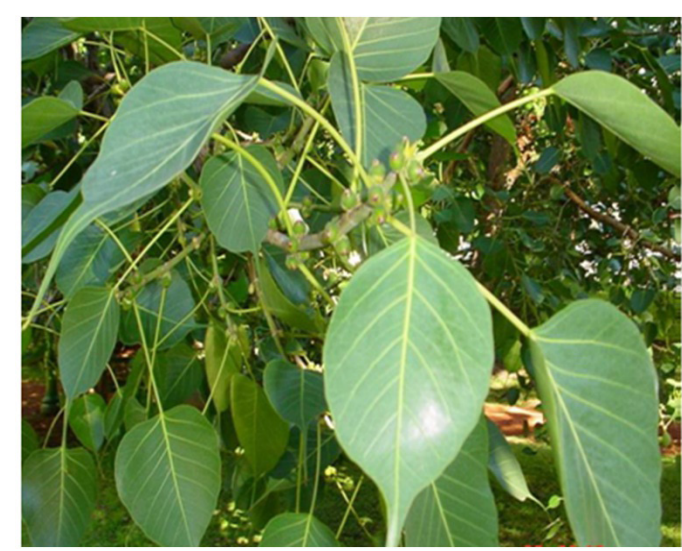

Figure 1A: The leaves of Ficus religiosa L.
Leaves were shade-dried and then finely powdered. The powder $(10 \mathrm{~g})$ was extracted with $100 \mathrm{ml}$ of distilled water using a Soxhlet apparatus (an apparatus which is used to remove or concentrate substances that may otherwise be very difficult to remove or concentrate if a manual process is used). The material thus obtained was filtered, and the resulting filtrate was concentrated to a dry mass by vacuum distillation; this was used for the current study.

\section{F. religiosa extract on the growth of CHPD crystals}

The putative activity of the plant extracts as inhibitors of CHPD crystal formation was investigated. The various concentrations (50, 75 and $100 \mathrm{~g}$ ) of the plant extract were dissolved in the respective 50, 75 and $100 \mathrm{ml}$ of distilled water to give 50,75 and $100 \%$ solution at the time of experiment. The prepared solutions were added to the formed CHPD gels and the results were noted. The experiments were repeated three times.

\section{Thermogravimetric analysis of CHPD crystals}

The Thermogravimetric Analysis (TGA) was performed on powdered samples by employing SDT Q600 V 8.3 Build 101 instruments set up. The thermogram was obtained by heating a sample from room temperature to $900^{\circ} \mathrm{C}$, in an atmosphere of nitrogen, with heating rate of $15^{\circ} \mathrm{C} / \mathrm{min}$ using a $-\mathrm{Al}_{2} \mathrm{O}_{3}$ as standard reference. The thermogram is shown in figure $1 \mathrm{~B}$. From this figure one can notice that hydrated calcium phosphate becomes anhydrous at $123.04^{\circ} \mathrm{C}$, thereafter, at $552^{\circ} \mathrm{C}$ it turns into Calcium Pyrophosphate $\left(\mathrm{Ca}_{2} \mathrm{P}_{2} \mathrm{O}_{7}\right)$. The melting point of $\mathrm{Ca}_{2} \mathrm{P}_{2} \mathrm{O}_{7}$ is $1230^{\circ} \mathrm{C}$; therefore, it is expected to remain stable up to the end of the analysis, that is, $900^{\circ} \mathrm{C}$. The following chemical reactions are expected to occur during the dehydration and decomposition stages.

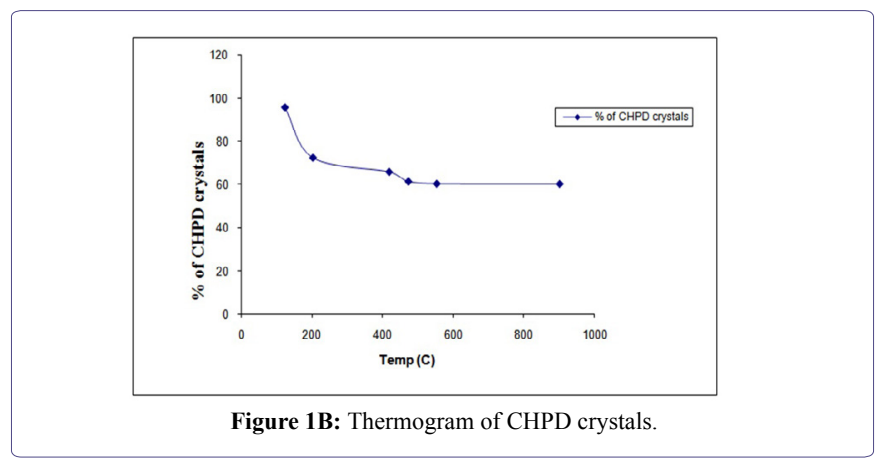

\section{Powder X-ray diffraction analysis of CHPD crystals}

Powder X-ray diffraction pattern was recorded on Bruker advance diffract meter within the range $2 \theta$ of 10 to $80^{\circ} \mathrm{C}$. The elemental composition of the specimen was determined using an elemental analyzer with energy dispersive X- Ray Fluorescence system (XRF). The surface morphology of the samples was evaluated by Scanning Electron Microscopy (SEM). Thermal analyses were performed using SDT Q600 V8.3 build 101 instrument. FTIR spectra of the grown crystals were recorded using Perkin Elmer, Spectrum Rx1 detector and $\mathrm{KBr}$ beam splitter.

\begin{tabular}{|c|c|c|c|c|c|c|c|c|}
\hline $\begin{array}{c}\text { SMS gel density } \\
\mathbf{g m} / \mathbf{c m}^{3}\end{array}$ & $\begin{array}{c}\text { Orthophosphoric } \\
\text { acid concentration }\end{array}$ & $\begin{array}{c}\mathbf{G e l}+\mathbf{H}_{\mathbf{3}} \mathbf{P O}_{\mathbf{4}} \\
\mathbf{p H}\end{array}$ & $\begin{array}{c}\text { Gel setting } \\
\text { Time (hr) }\end{array}$ & $\begin{array}{c}\text { Concentration of } \\
\text { Supernatant } \\
\mathbf{C a C l}(\mathbf{M})\end{array}$ & $\begin{array}{c}\text { Liesegang } \\
\text { ring formation } \\
\text { (hr) }\end{array}$ & $\begin{array}{c}\text { Growth period } \\
\text { (days) }\end{array}$ & $\begin{array}{c}\text { Types of crystals } \\
\text { (dals size (cm) }\end{array}$ & $\begin{array}{c}\text { Harvested crys- } \\
\text { tals }\end{array}$ \\
\hline \multirow{2}{*}{1.04} & $0.5 \mathrm{~N}$ & 6.4 & 34 & 1 & 12 & 60 & Single crystals & $1.7-2.0$ \\
\cline { 2 - 8 } & $1 \mathrm{~N}$ & 7.3 & 24 & 1 & 24 & 35 & Rod, stars shaped & $2.3-3$ \\
\hline
\end{tabular}

Table 1: Growth parameters of CHPD crystals. 
Citation: Baskaraboopathy A, Rajaram MG, Elizabeth AR, Eevera T, Jayakumar T (2017) An Aqueous Extract of the Leaves of Ficus religiosa Inhibits the Growth of Urinary Calcium Hydrogen Phosphate Dihydrate Crystals-An In-Vitro Study. J Altern Complement Integr Med 3: 041.

- Page 3 of 6 •

\section{Results}

The first Liesegang ring was observed within 12 min of pouring the solution. In total, 18 Liesegang rings were observed over time. The elongated platelet shape CHPD crystals grew within the rings. In addition, platelets originated from a single point, that is, star shaped crystals were observed. Figure 2 shows the schematic diagram of the growth of crystals at $12^{\text {th }}$ day (Figure 2A), an enlarged picture (Figure 2B) and the morphology (Figure 2C) of harvested CHPD crystals The largest crystal was $18 \mathrm{~mm}$ in length. The crystals were characterized by Fourier transform infrared spectroscopy, thermogravimetric analysis, scanning electron microscopy and powder x-ray diffraction methods, and confirmed to be CHPD.

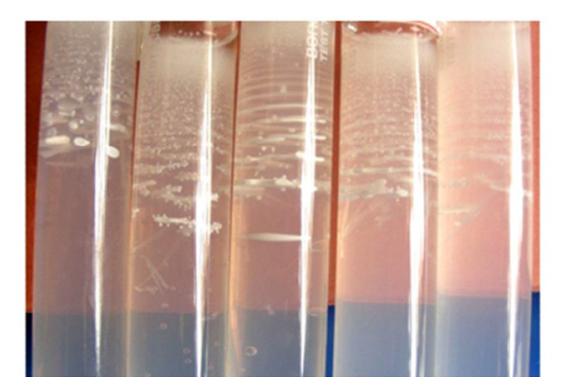

Figure 2A: Growth of CHPD crystals at the end of $12^{\text {th }}$ days.

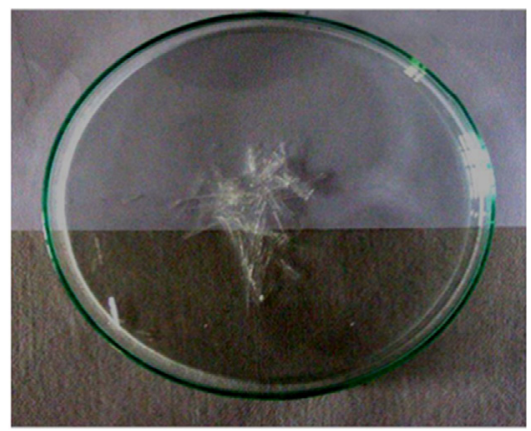

Figure 2B: Structure of harvested CHPD crystals.
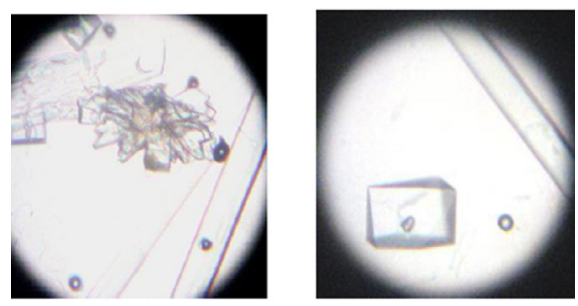

Figure 2C: Micro crystal growth of CHPD under modified gel technique.

The morphological characters of harvested CHPD crystals show (Figure 2C) that the crystals are in needle or star shaped. The crystal length ranges about $2.3-3 \mathrm{~cm}$, the crystal breadth is $1-2 \mathrm{~mm}$ and their thickness was about $1 \mathrm{~mm}$ (Table 2). The thermogram was obtained by heating a sample from room temperature to $900^{\circ} \mathrm{C}$ in an atmosphere of nitrogen with heating rate of $15^{\circ} \mathrm{C} / \mathrm{min}$, using $\alpha-\mathrm{Al}_{2} \mathrm{O}_{3}$ as standard reference. A picture of thermogram and the thermal composition of CHPD crystals are shown in figure 1B and table 3 , respectively.

\begin{tabular}{|c|c|}
\hline \multicolumn{2}{|c|}{ Crystal characteristics } \\
\hline Color & Glassy/Transparent \\
\hline Shape & Needle or star shaped \\
\hline Length & $2.3-3 \mathrm{~cm}$ \\
\hline Breadth & $1-2 \mathrm{~mm}$ \\
\hline Thickness & $1 \mathrm{~mm}$ \\
\hline \multicolumn{2}{|c|}{ Table 2: Morphological characteristics of harvested CHPD crystals. } \\
\hline
\end{tabular}

\begin{tabular}{|c|c|c|}
\hline \multicolumn{3}{|c|}{ Thermo gravimetric analysis } \\
\hline Points & Temperature & Presence of CHPD crystal \\
\hline & $\left({ }^{\circ} \mathrm{C}\right)$ & $(\%)$ \\
\hline 1 & 123.04 & 95.77 \\
\hline 2 & 202.19 & 72.55 \\
\hline 3 & 417.72 & 66.06 \\
\hline 4 & 472.08 & 61.63 \\
\hline 5 & 552.19 & 60.62 \\
\hline 6 & 900 & 60.52 \\
\hline
\end{tabular}

Table 3: Thermal decomposition of CHPD crystals.

The X-ray powder diffraction of the cultured CHPD crystals (Table 4) was matched with the organic database-using computer and the results were consistent with CHPD X-ray powder diffract gram (Figure 3A) produced during the $\mathrm{x}$-ray scans. The peaks positions represent where the $\mathrm{x}$-ray beam has been diffracted by the CHPD crystals. The set of $d$ spacing (the distance between the adjacent planes of atoms), which represents the unique "finger prints" of the crystals can

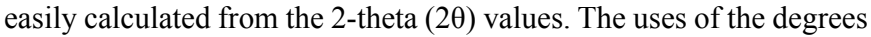
2 -theta in depicting $\mathrm{x}$-ray powder diffraction scans is a matter convention and can easily be related peak to the JC-PDF (Joint Committee for Powder x-ray Diffraction File). The comparing the measured diffract grams with JC-PDF has identified constituents present in the CHPD crystals.

\begin{tabular}{|c|c|c|c|c|}
\hline Position & Height (cm) & FWHM ('2Th.) & d-spacing & Relative \\
\hline ( $\left.{ }^{0} 2 \mathrm{Th}.\right)$ & & & $\left(\mathrm{A}^{0}\right)$ & Intensity (\%) \\
\hline 11.8115 & 2161.39 & 0.0816 & 7.48647 & 100 \\
\hline 21.0811 & 115.93 & 0.1632 & 4.21087 & 5.36 \\
\hline 23.5604 & 400.54 & 0.0816 & 3.77305 & 18.53 \\
\hline 29.4101 & 567.86 & 0.0816 & 3.03454 & 26.27 \\
\hline 30.6265 & 134.37 & 0.1632 & 2.91674 & 6.22 \\
\hline 34.2736 & 102.36 & 0.1632 & 2.61424 & 4.74 \\
\hline 35.5171 & 25.67 & 0.4896 & 2.52552 & 1.19 \\
\hline 37.1007 & 30.47 & 0.4896 & 2.42127 & 1.41 \\
\hline 41.6905 & 98.08 & 0.102 & 2.1647 & 4.54 \\
\hline 48.0095 & 225.89 & 0.1224 & 1.8935 & 10.45 \\
\hline 57.0612 & 76.08 & 0.2448 & 1.61276 & 3.52 \\
\hline 77.7491 & 213.8 & 0.0816 & 1.22734 & 9.89 \\
\hline
\end{tabular}

The major and interesting finding of this study is the extract of the leaves of $F$. religiosa inhibited the formation of CHPD crystals (Figure 3B). The results of the decreased optical density with the increase in concentration of the extract of $F$. religiosa indicating that 
decreased the nucleation of CHPD crystals. The OD was highest in positive control i.e., in the absence of the extract and it was lowest at the highest concentration of $F$. religiosa $(100 \%)$. The crystals formed in the presence of F. religiosa were less than that in the control, showing that crystals were less aggregated.

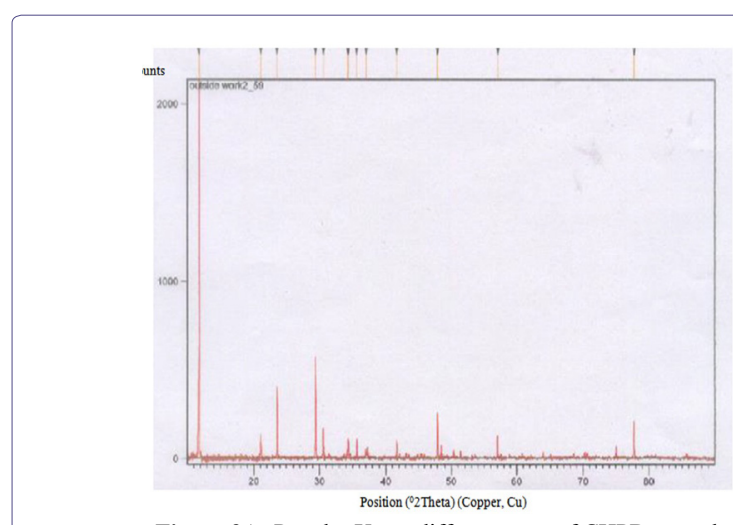

Figure 3A: Powder X-ray diffractogram of CHPD crystals.

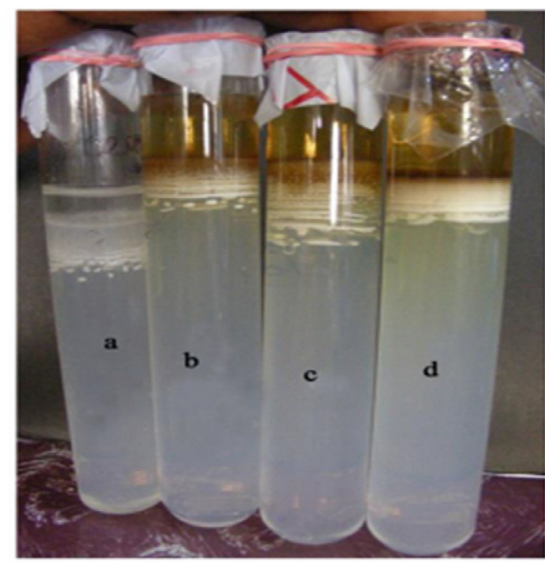

Figure 3B: Effect of an extract of the leaves of $F$. religiosa on CHPD crystal growth: a) (CHPD crystal), b) (CHPD crystal treated with $50 \%$ F. religiosa extract), c) (CHPD crystal treated with $75 \%$ F. religiosa extract) and d) (CHPD crystal treated with $100 \%$ F. religiosa extract).

\section{Discussion}

Ficus religiosa is reported to have several therapeutic uses in folk medicine. Their leaf juice has been used for the treatment of asthma, cough, sexual disorders, diarrhea, hematuria, ear-ache and toothache, migraine, eye troubles, gastric problems and scabies; leaf decoction has been used as an analgesic for toothache; fruits for the treatment of asthma, other respiratory disorders and scabies; stem bark is used in gonorrhea, bleeding, paralysis, diabetes, diarrhea, bone fracture, antiseptic, astringent and antidote [19]. In Ayurveda, it is claimed that F. religiosa possesses anticonvulsant activity [20]. Acetyl cholinesterase inhibitory and antianxiety activities of this plant were also studied $[13,21]$. However, there is no information about their inhibitory effects on kidney stone and/or CHPD, oxalate formation. The main findings of the present study show that an extract of the leaves of $F$. religiosa inhibited the formation of CHPD crystals in a concentration dependent manner; less and smaller particles were formed with increasing concentrations of the extract. This property of plants may be important in preventing the growth of kidney stone. Aggregation may be an important factor in the genesis of stones [22]. Chaudhary et al., have suggested that the limiting factors in stone formation may affect the crystal growth, because particles may become large enough to occlude the urinary tract, leading to stone formation [23]. The herb extracts may contain substances that inhibit the growth of CHPD crystals.

It has been reported that oxalate plays an important role in stone formation and has about 15 -fold greater effect than urinary calcium $[24,25]$. In the present study, CHPD is formed competently in an in vitro gel system. Joshi et al., have reported the inhibitory effects of litholytic medicinal plants Tribulus terrestris L. (Zygophyllaceae) and Bergenia ligulata L. (Saxifragaceae) on the growth of CHPD crystals [26]. They have described that calcium chloride containing supernatant solution produced Liesegang rings in the gel and needle, platelet and star-shape CHPD crystals which are grown within the rings. The calcium chloride in the supernatant solutions was modified the diffusion process and thus the periodic precipitation and the number of Liesegang rings reduced by the addition of aqueous extracts of $T$. terrestris and B. ligulata [26]. They have also noted the maximum length of the crystals reduced due to inhibition produced by the addition of aqueous extracts of B. ligulata and T. terrestris. Several lines of evidence indicated that there are various compounds exhibiting inhibitory actions on the growth of urinary stones and crystals, such as tartrates are good inhibitors of stones in natural and artificial urine [27]. In the present study, an extract of F. religiosa was used to study the growth behavior of CHPD crystals. F. religiosa inhibits the growth of CHPD crystals. This can be verified from the results of the formation of CHPD crystals.

Numerous inhibitors have been identified in urine for the calcium phosphate and calcium oxalate crystal systems. Magnesium, citrate, pyrophosphate and nephrocalcein are the inhibitors in the calcium phosphate crystal system [28]. The in vitro formation of urinary stones and the generation of spherulites of calcium phosphate in gels, as well as the overgrowth with calcium oxalate using a new flow model of crystallization have been studied by Achilles et al. [29]. Ethanolic extract of $T$. terrestris fruits were found to exhibited protection against uroliths induced by glass bead implantation in rats [30]. In another study, an administration of a drug containing $T$. terrestris to sodium glycolate fed rats produced a significant decrease in urinary oxalate excretion and a significant increase in urinary glyoxylate excretion [31]. Recently various herbal plants such as Flos carthami, Costus igneus, Tribulus terrestris and Scoparia dulcis have successfully proved as prophylactic and curative medicine for urolithiasis [32-35]. Another recent in vitro study showed that leaf extracts of I. eriocarpa possesses potent antiurolithiatic activity [36]. So remove also, the results of present study corroborate findings with the results of the above investigations.

\section{Conclusion}

The findings of the present investigation shed light on the inhibitive processes occurring in an extract of the leaves of $F$. religios $a$ on the growth of CHPD crystals. Despite, the process of stone formation in the human body is fairly complicated the present study provided basic information, under laboratory conditions, which led us to identify new inhibiting solutions of stone growth. Further in vivo investiga- 
tions will be done in the future to clarify the molecular mechanism of the inhibitory action of $F$. religiosa on the growth of CHPD crystals. The results of this study may suggest that $F$. religiosa can be used as therapeutic agent for the treatment of urinary calculi or their prevention.

\section{Acknowledgement}

The authors thank Periyar Maniammai University, Vallam-613403, Thanjavur, Tamil Nadu, India for the instrumentation facility provided.

\section{References}

1. Araújo Viel T, Diogo Domingos C, da Silva Monteiro AP, Riggio Lima-Landman MT, Lapa AJ, et al. (1999) Evaluation of the antiurolithiatic activity of the extract of Costus spiralis Roscoe in rats. J Ethnopharmacol 66: 193-198.

2. Wolf JS Jr, Stoller ML (1994) Inhibition of calculi fragment growth by metal-bisphosphonate complexes demonstrated with a new assay measuring the surface activity of urolithiasis inhibitors. J Urol 152: 1609-1614.

3. Menon M, Parulkar BG, Drach GW (1998) Campbell's Urology ( $9^{\text {th }}$ edn) Walter Burns Saunders, Philadelphia, Pennsylvania, USA.

4. Colobawalla BN (1971) Incidence of urolithiasis in India. ICMR Tech Rep 8: 42-51.

5. Bouanani S, Henchiri C, Migianu-Griffoni E, Aouf N, Lecouvey M (2010) Pharmacological and toxicological effects of Paronychia argentea in experimental calcium oxalate nephrolithiasis in rats. J Ethnopharmacol 129: $38-45$.

6. Vanachayangkul P, Byer K, Khan S, Butterweck V (2010) An aqueous extract of Ammi visnaga fruits and its constituents khellin and visnagin prevent cell damage caused by oxalate in renal epithelial cells. Phytomedicine 17: 653-658

7. Prasad PV, Subhaktha PK, Narayana A, Rao MM (2006) Medico-historical study of "aśvattha" (sacred fig tree). Bull Indian Inst Hist Med Hyderabad 36: $1-20$.

8. Singh D, Goel RK (2009) Anticonvulsant effect of Ficus religiosa: role of serotonergic pathways. J Ethnopharmacol 123: 330-334.

9. Choudhary GP (2006) Evaluation of ethanolic extract of Ficus religiosa bark on incision and excision wounds in rats. Planta Indica 2: 17-19.

10. Nair R, Chanda SV (2007) Antibacterial activities of some medicinal plants of the Western Region of India. Turkish Journal of Biology 31: 231-236.

11. Pandit R, Phadke A, Jagtap A (2010) Antidiabetic effect of Ficus religio$s a$ extract in streptozotocin-induced diabetic rats. J Ethnopharmacol 128 : $462-466$.

12. Sreelekshmi R, Latha PG, Arafat MM, Shyamal S, Shine VJ, et al. (2007) Anti-inflammatory, analgesic and anti-lipid peroxidation studies on stem bark of Ficus religiosa Linn. Natural Product Radiance 6: 377-381.

13. Vinutha B, Prashanth D, Salma K, Sreeja SL, Pratiti D, et al. (2007) Screening of selected Indian medicinal plants for acetylcholinesterase inhibitory activity. J Ethnopharmacol 109: 359-363.

14. Haneef J, Parvathy M, Thankayyan R SK, Sithul H, Sreeharshan S (2012) Bax translocation mediated mitochondrial apoptosis and caspase dependent photosensitizing effect of Ficus religiosa on cancer cells. PLoS One 7: 40055 .
15. Choudhari AS, Suryavanshi SA, Kaul-Ghanekar R (2013) The aqueous extract of Ficus religiosa induces cell cycle arrest in human cervical cancer cell lines SiHa (HPV-16 Positive) and apoptosis in HeLa (HPV-18 positive). PLoS One 8: 70127.

16. Gregory M, Divya B, Mary RA, HipolithViji MM, Kalaichelvan VK, et al. (2013) Anti-ulcer activity of Ficus religiosa leaf ethanolic extract. Asian Pac J Trop Biomed 3: 554-556.

17. Antony JJ, Sithika MA, Joseph TA, Suriyakalaa U, Sankarganesh A, et al. (2013) In vivo antitumor activity of biosynthesized silver nanoparticles using Ficus religiosa as a nanofactory in DAL induced mice model. Colloids Surf B Biointerfaces 108: 185-190.

18. Joshi VS, Joshi MJ (2003) FTIR spectroscopic, thermal and growth morphological studies of calcium hydrogen phosphate dihydrate crystals. Cryst Res Technol 38: 817-821.

19. Ripu MK, Rainer WB (2006) Ficus (Fig) species in Nepal: A review of diversity and indigenous uses. Lyonia 11:85-97.

20. Vyawahare NS, Khandelwal AR, Batra VR, Nikam AP (2007) Herbal anticonvulsants. J Herb Med Toxicol 1: 9-14.

21. Ratnasooriya WD, Jayakody JR, Dharmasiri MG (1998) An aqueous extract of trunk bark of Ficus religiosa has anxiolytic activity. Med Sci Res 26: 817-819.

22. Fleisch H (1978) Inhibitors and promoters of stone formation. Kidney Int 13: $361-371$

23. Chaudhary A, Singla SK, Tandon C (2010) In vitro Evaluation of Terminalia arjuna on Calcium Phosphate and Calcium Oxalate Crystallization. Indian J Pharm Sci 72: 340-345.

24. Karadi RV, Gadge NB, Alagawadi KR, Savadi RV (2006) Effect of Moringa oleifera Lam. root-wood on ethylene glycol induced urolithiasis in rats. J Ethnopharmacol 105: 306-311.

25. Soundararajan P, Mahesh R, Ramesh T, Begum VH (2006) Effect of Aerva lanata on calcium oxalate urolithiasis in rats. Indian J Exp Biol 44: 981986.

26. Joshi VS, Parekh BB, Joshi MJ, Vaidya AD (2005) Inhibition of the growth of urinary calcium hydrogen phosphate dihydrate crystals with aqueous extracts of Tribulus terrestris and Bergenia ligulata. Urol Res 33: 80-86.

27. Croft K, Adair JH, Bowyer R, Brockis JG (1984) Urinary stone. In: Ryall RL, et al. (eds). Churchill Livingstone, London, UK.

28. Ito H, Coe FL (1997) Acidic peptide and polyribonucleotide crystal growth inhibitors in human urine. Am J Physiol Renal Physiol 233: 455-463.

29. Achilles W, Jocket U, Schaper A, Burk B, Riedmiller H (1995) In vitro formation of "urinary stones": Generation of spherulites of calcium phosphate in gel and overgrowth with calcium oxalate using a new flow model of crystallization. Scanning Microsc 9: 577-585.

30. Anand R, Pathnaik GK, Kulshreshtha DK, Dhawan BN (1994) Activity of certain fractions of Tribulus terrestris fruits against experimentally induced urolithiasis in rats. Indian J Exp Biol 32: 548-552.

31. Sangeeta D, Sidhu H, Thind SK, Nath R (1994) Effect of Tribulus terrestris on oxalate metabolism in rats. J Ethnopharmacol 44: 61-66.

32. Lin WC, Lai MT, Chen HY, Ho CY, Man KM, et al. (2012) Protective effect of Flos carthami extract against ethylene glycol-induced urolithiasis in rats. Urol Res 40: 655-661.

33. Manjula K, Rajendran K, Eevera T, Kumaran S (2012) Effect of Costus igneus stem extract on calcium oxalate urolithiasis in albino rats. Urol Res 40: 499-510. 
Citation: Baskaraboopathy A, Rajaram MG, Elizabeth AR, Eevera T, Jayakumar T (2017) An Aqueous Extract of the Leaves of Ficus religiosa Inhibits the Growth of Urinary Calcium Hydrogen Phosphate Dihydrate Crystals-An In-Vitro Study. J Altern Complement Integr Med 3: 041.

- Page 6 of 6 •

34. Aggarwal A, Tandon S, Singla SK, Tandon C (2010) Diminution of oxalate induced renal tubular epithelial cell injury and inhibition of calcium oxalate crystallization in vitro by aqueous extract of Tribulus terrestris. Int Braz J Urol 36: 480-488.

35. Rajan R, Vedi M, Sridharan B, Himaja M, Sabina EP, Nambiraj NA (2014) In vitro and in vivo study on the effect of Scoparia dulcis in inhibiting the growth of urinary crystals. Int J Phytomed 6: 617-624.
36. Das M, Malipeddi H, Nambiraj NA, Rajan R (2016) Phytochemical analysis, antioxidant activity and in vitro growth inhibition of struvite crystals by I pomoea eriocarpa leaf extracts. J Food Biochem 40: 148-160. 